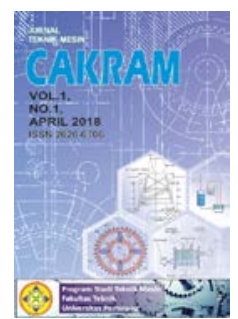

\title{
ANALISIS PENGARUH JUMLAH SUDU WATER PUMP PADA MOBIL “ $X$ ” TERHADAP TERJADINYA OVERHEATING
}

\author{
Jaim $^{1}$ \\ ${ }^{1}$ Program Studi Teknik Mesin, Universitas Pamulang, Jl. Surya Kencana No. 1, Tangerang Selatan, Indonesia \\ E-mail : dosen00892@unpam.ac.id
}

Masuk : 24 Agustus 2019

Direvisi : 12 September 2019

Disetujui :26 September 2019

\begin{abstract}
Abstrak : Salah satu alternatif untuk menjaga penghematan penggunaan bahan bakar adalah dengan memaksimalkan efisiensi dari kendaraan tersebut. Salah satu dari peningkatan efisiensi itu yaitu dengan peningkatan kinerja sistem pendingin agar tidak terjadi overheating. Water pump yang berfungsi dalam mendistribusikan cairan pendingin pada mesin, salah satu dari komponennya yang sangat berpengaruh adalah sudu / impeller. Studi kasus dalam penelitian ini adalah pada mobil x yang selalu overheating. Dalam kasus ini peneliti fokus kepada jumlah sudu pada water pump asli mobil x tersebut yang berjumlah 6 buah sudu yang mempunyai sudut kemiringan $45^{\circ}$, dengan memvariasikan sudunya yang berjumlah 7 , 8, dan 9 buah sudunya yang berdiameter $65 \mathrm{~mm}$, tebalnya 0,5 $\mathrm{mm}$ dan tingginya $15 \mathrm{~mm}$. Hasil dari pengujian mendapatkan tingkat efisiensi dan penolakan overheating pada sudu 9 buah dengan teknik perhitungan menggunakan full factorial design.
\end{abstract}

Kata Kunci : Water Pump, sudu, radiator coolant, Rpm, Pertalite

Abstract : An alternative to reduce fuel requirements is to maximize the efficiency of the vehicle. One of the efficiency improvements is by increasing the performance of the cooling system to prevent overheating. Water pump that functions to distribute coolant to the engine One of the most influential components in water pump is the blade or impeller. This study case is on a car $x$ which is always overheating. In this case, the researcher focused on the number of impellers on the original car $x$ water pump which amounted to 6 impellers a 45 degree slope, by varying the number of 7, 8 and 9 angles with the diameter of 65 $\mathrm{mm}$, the thickness of $0.5 \mathrm{~mm}$ and the height is $15 \mathrm{~mm}$. The result of the tests obtained efficiency and rejection rates overheating in impeller 9 with the calculation technique using full factorial design.

Keywords: Water Pump, impeller, radiator coolant, Rpm, Pertalite

\section{PENDAHULUAN}

Berdasarkan letak geografis indonesia berada di garis katulistiwa yang beriklim tropis dan kondisi lalu lintas yang sangat padat / macet ${ }^{[1]}$, mengakibatkan kondisi sistem pendingin mesin bekerja ekstra keras dalam membuang panas mesin, baik secara konduksi maupun konveksi dan radiasi. Akibat dari proses pendinginan yang tidak bekerja maksimal dapat menimbulkan temperatur pada mesin yang berlebih (overheat), batas maksimum tingkat panas mesin motor bakar antara $75^{\circ} \mathrm{C}-90^{\circ} \mathrm{C}$. Banyak dampak merugikan yang ditimbulkan apabila sisitem pendingin tidak bekerja dengan baik antara lain ; pemakaian bahan bakar yang boros, tenaga mesin yang berkurang dan paling fatal adalah mesin menjadi macet sehingga mengakibatkan kerusakan komponen-komponen mesin ${ }^{[3]}$

Water pump adalah salah satu komponen dalam sistem pendingin mesin dan sudu merupakan komponen penting yang berfungsi untuk memindahkan atau memompa cairan. Suhartoyo dan joko Yunianto Prihatin ${ }^{[2]}$ dan mereka berpendapat bahwa faktor jumlah sudu lebih dominan berpengaruh terhadap pencapaian suhu pendinginan 
air radiator paling rendah dibandingkan dengan faktor jarak pemasangan kipas, dan sewaktu impeller berputar air pada pusat terisap dan terlempar ke arah luar oleh gaya sentrifugal pada keliling impeller. ${ }^{[10]}$

\section{METODOLOGI}

Dalam penelitian ini dilakukan dengan langkah-langkah sebagai berikut.

Identifikasi Masalah :

Sistem pendingin mesin yang baik pada motor bakar sangat berpengaruh pada efisiensi.

Rumusan Masalah :

Bagaimana pengaruh variasi sudu untuk mencegah terjadinya overheat

Tujuan Penelitian :

a) Berapa besar pengaruh jumlah sudu yang ditunjukan oleh suhu mesin, suhu radiator , laju aliran dan water coolant yang bervariasi terhadap kinerja sistem pendingin.

b) Mengetahui jumlah sudu impeller yang paling optimal.

a) Variabel terikat : Jumlah sudu dan cairan pendingin yang bervariasi

b) Variabel bebas : Kinerja sistem pendingin yang ditunjukan oleh suhu mesin, suhu radiator, laju aliran dan konsumsi bahan bakar

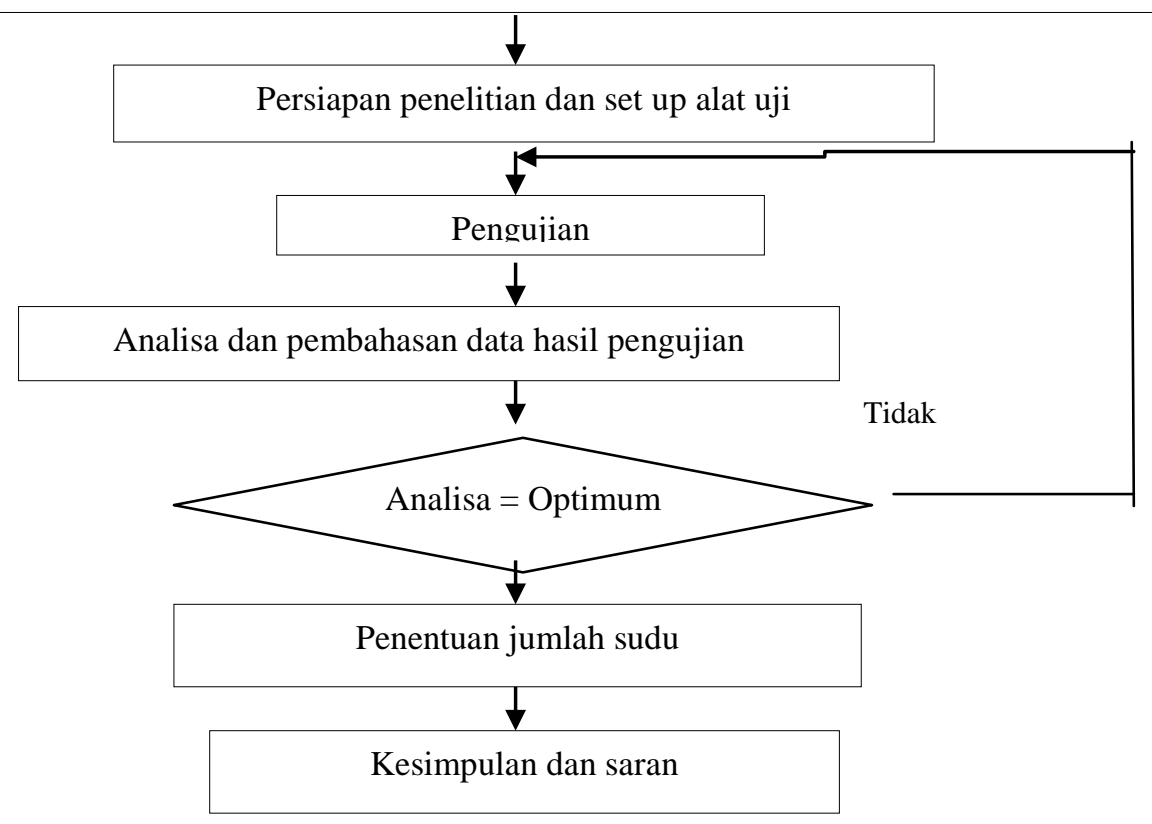

Gambar 1.Diagram alur Penelitian 
Dalam melakukan penelitian ini diagram alir ditunjang dengan menggunakan hubungan sebab akibat.

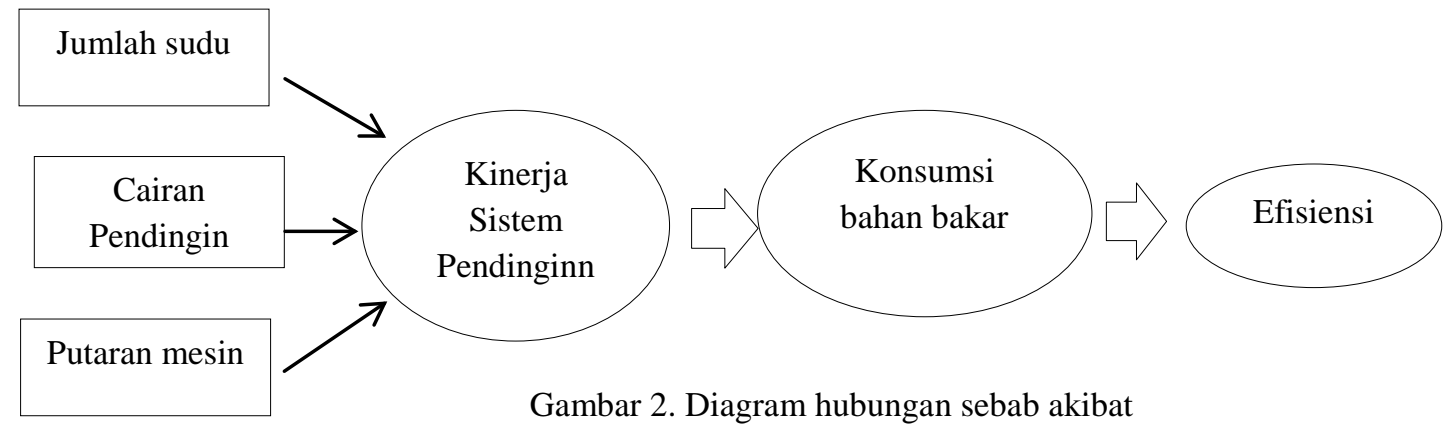

\section{Teknik Pengumpulan data}

Teknik pengumpulan data diambil dari hasil pengujian pada mesin penguji, di peroleh data yang akan diambil dengan menggunakan variasi sudu impeller yang berjumlah 6, 7, 8, dan 9 buah dengan rentang waktu 10 menit untuk sekali pengujian, temperature pada ruangan pengujian $30^{\circ}$, kecepatan angin sekitar $9,2 \mathrm{~m} / \mathrm{s}$ dan putaran mesin $1000 \mathrm{rpm}, 1500 \mathrm{rpm}, 2000 \mathrm{rpm}, 2500 \mathrm{rpm}$. Untuk mengetahui tingkat panas dan konsumsi bahan bakar yang dipakai, dengan mengamati langsung hasil dari pengujian atau eksperimen menyimpulkan dan menentukan hasil dari penelitian yang baik. Data yang diambil antara lain :

a. Melakukan pengukuran suhu radiator pada awal sebelum pengujian dan diakhir setiap pengujian.

b. Melakukan pengukuran suhu mesin pada awal sebelum pengujian dan diakhir setiap pengujian menggunakan thermocouple.

c. Menggunakan gelas ukur dengan ukuran $100 \mathrm{ml}$ dan $1000 \mathrm{ml}$ untuk mengukur konsumsi bahan bakar yang digunakan pada setiap pengujian.

d. Pengukuran kecepatan debit air menggunakan water flow.

\section{Teknik Pengolahan data}

Data kuantitatif yang diperoleh dari hasil pengujian dianalisis dengan menggunakan desain full factorial dan untuk menentukan hasil penelitian yang baik diperoleh dari buku-buku referensi dan sumber lain yang relevan dengan penelitian ini, kemudian data tersebut dituangkan dalam bentuk tabel dan grafik

\section{Teknik Analisis data}

Analisis data pada penelitian ini menggunakan desain full factorial, untuk menguji pengaruh panas pada pendinginan terhadap penggantian jumlah sudu dan pengaruh antara cairan pendingin dan temperature terhadap konsumsi bahan bakar yang diukur dengan menggunakan gelas ukur. Sehingga dapat mengetahui pengaruh sederhana, pengaruh utama dan pengaruh interaksi, sebagai berikut :

a. Pengaruh utama faktor A adalah :

$$
\begin{aligned}
\mathrm{A} & =1 / 2 \cdot n\left\{\left(\mathrm{a}_{2} \mathrm{~b}_{2}-\mathrm{a}_{1} \mathrm{~b}_{2}\right)+\left(\mathrm{a}_{2} \mathrm{~b}_{1}-\mathrm{a}_{1} \mathrm{~b}_{1}\right)\right\} \\
& =1 / 2 \cdot n\left\{\left(\mathrm{a}_{2} \mathrm{~b}_{2}+\mathrm{a}_{2} \mathrm{~b}_{1}\right)-\left(\mathrm{a}_{1} \mathrm{~b}_{2}+\mathrm{a}_{1} \mathrm{~b}_{1}\right)\right\}
\end{aligned}
$$

b. Pengaruh utama Faktor B adalah :

$$
\begin{aligned}
\mathrm{B} & =1 / 2 \cdot \mathrm{n}\left\{\left(\mathrm{a}_{2} \mathrm{~b}_{2}+\mathrm{a}_{2} \mathrm{~b}_{1}\right)+\left(\mathrm{a}_{1} \mathrm{~b}_{2}+\mathrm{a}_{1} \mathrm{~b}_{1}\right)\right\} \\
& =1 / 2 . \mathrm{n}\left\{\left(\mathrm{a}_{2} \mathrm{~b}_{2}+\mathrm{a}_{1} \mathrm{~b}_{2}\right)-\left(\mathrm{a}_{1} \mathrm{~b}_{2}+\mathrm{a}_{1} \mathrm{~b}_{1}\right)\right\}
\end{aligned}
$$

c. Interaksi antara jumlah sudu dan rpm didefinisikan sebagai :

$$
\begin{aligned}
\mathrm{AB} & =1 / 2 \cdot n\left\{\left(\mathrm{a}_{2} \mathrm{~b}_{2}-\mathrm{a}_{1} \mathrm{~b}_{2}\right)-\left(\mathrm{a}_{1} \mathrm{~b}_{2}-\mathrm{a}_{1} \mathrm{~b}_{1}\right)\right\} \\
& =1 / 2 \cdot \mathrm{n}\left\{\left(\mathrm{a}_{2} \mathrm{~b}_{2}+\mathrm{a}_{1} \mathrm{~b}_{1}\right)-\left(\mathrm{a}_{1} \mathrm{~b}_{2}+\mathrm{a}_{2} \mathrm{~b}_{1}\right)\right\}
\end{aligned}
$$

Faktor dan level yang di selidiki adalah sebagai berikut :
a. Jumlah sudu (A)
b. cairan (B)
c. Putaran mesin ( $\mathrm{n})$

\section{HASIL DAN PEMBAHASAN}


Data yang dihasilkan pada penelitian ini adalah kinerja sistem pendingin mesin terhadap suhu radiator, suhu mesin dari perlakuan jumlah sudu, jenis cairan dan putaran mesin yang berbeda dengan responnya adalah efisiensi dan pencegahan terjadinya overheating. yang tersaji pada tabel

A. Hasil Pengujian variasi jumlah sudu dengan cairan radiator coolant,

Tabel 1. Data pengujian suhu radiator dari perlakuan variasi jumlah sudu,dan putaran mesin.

\begin{tabular}{|c|c|c|c|c|c|}
\hline \multirow{4}{*}{$\begin{array}{c}\text { Jenis } \\
\text { cairan }\end{array}$} & \multirow{4}{*}{ rpm } & \multicolumn{4}{|c|}{ Unit aktivitas Jumlah sudu } \\
\hline & & \multicolumn{4}{|c|}{ Suhu Radiator $A(q)^{0} \mathrm{C}$} \\
\hline & & 6 & 7 & 8 & 9 \\
\hline & & $q^{0}$ & $q^{0}$ & $q^{0}$ & $q^{0}$ \\
\hline \multirow{4}{*}{$\begin{array}{l}\text { Radiator } \\
\text { coolant } \\
\text { yang } \\
\text { mengand } \\
\text { ung } \\
\text { ethylene } \\
\text { glycol }\end{array}$} & 1000 & 75.9 & 75.6 & 70.2 & 68.4 \\
\hline & 1500 & 76.6 & 75.3 & 74.1 & 71.6 \\
\hline & 2000 & 82.4 & 80.2 & 77.2 & 77.2 \\
\hline & 2500 & 85.2 & 84.6 & 83.5 & 82.4 \\
\hline \multicolumn{2}{|c|}{ Jumlah } & 320.1 & 315.7 & 305 & 299.6 \\
\hline \multicolumn{2}{|c|}{ Rata - rata } & 80 & 78.9 & 76.2 & 74.9 \\
\hline
\end{tabular}

Data yang diperoleh dari hasil pengujian bahwa nilai efektivitas radiator coolant yang mengandung ethylene glycol dan memiliki nilai konstrate +8 , dapat dilihat pada grafik di bawah ini :

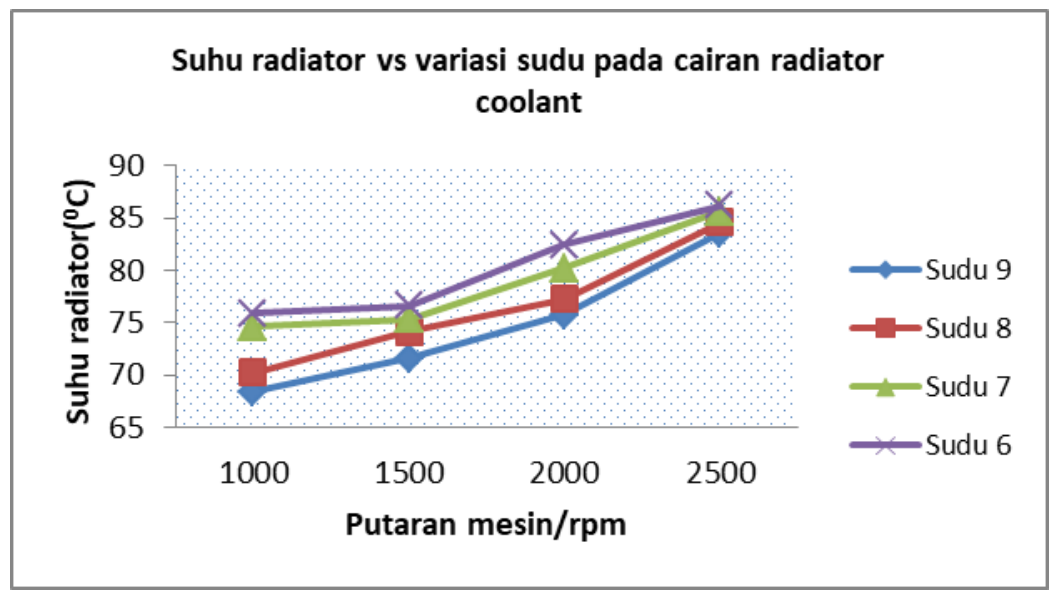

Gambar 3. Grafik pengaruh jumlah sudu terhadap suhu radiator

Pada grafik 3. Menjelaskan bahwa tingkat daya serap kalor pada sudu 9 sekitar 24,9 Watt (5,15\%), pada sudu 8 sekitar 21,5 watt (3,42\%), pada sudu 7 sekitar 16,9 Watt (1,87\%)dan Pada sudu 6 tingkat penyerapan mencapai $1,48 \mathrm{~kW}$ atau sekitar $1,75 \%$. Setelah melakukan pengacakan pada suhu radiator sebanyak 48 kali, maka didapatkan hasil Uji - F sebgaia berikut :

Hasil dari uji F, Sebagai berikut :

- $\quad$ Efek Faktor A : F hitung $>$ F tabel (0.01) berbeda sangat nyata

- $\quad$ Efek Faktor B : F hitung $<$ F tabel $(0.05)$ berbeda tidak nyata

- $\quad$ Efek Interaksi A x B $\quad$ : F tabel (0.05) $<$ F hitung $<$ F tabel (0.01) tidak nyata 
Nilai $\left(\mathrm{F}_{\text {interaksi }}=-8.24\right)<$ nilai $\mathrm{F}_{0.05(\mathrm{db} 1=12)}=1.96$, sehingga pada taraf nyata $\alpha=5 \%$ tidak terjadi pengaruh interaksi antara salah satu perubahan jumlah sudu dengan suhu radiator nyata

Tabel 2. Data hasil pengujian suhu mesin dari perlakuan variasi jumlah sudu,dan putaran mesin.

\begin{tabular}{|c|c|c|c|c|c|}
\hline \multirow{4}{*}{ Jenis cairan } & \multirow{4}{*}{$\begin{array}{l}\text { Rpm } \\
\text { (n) }\end{array}$} & \multicolumn{4}{|c|}{ Unit aktivitas Jumlah sudu } \\
\hline & & \multicolumn{4}{|c|}{ Suhu mesin $A(q)^{0} \mathrm{C}$} \\
\hline & & 6 & 7 & 8 & 9 \\
\hline & & $q^{0}$ & $\mathrm{q}^{0}$ & $\mathrm{q}^{0}$ & $q^{0}$ \\
\hline \multirow{4}{*}{$\begin{array}{c}\text { Radiator coolant } \\
\text { yang mengandung } \\
\text { ethylene glycol }\end{array}$} & 1000 & 43.8 & 39 & 38.3 & 31.9 \\
\hline & 1500 & 44.9 & 40.4 & 40 & 37.2 \\
\hline & 2000 & 46.8 & 42.2 & 41.9 & 40.4 \\
\hline & 2500 & 52.8 & 48.3 & 47.5 & 44.2 \\
\hline \multicolumn{2}{|l|}{ Jumlah } & 188.3 & 169.9 & 167.7 & 153.7 \\
\hline \multicolumn{2}{|l|}{ Rata - rata } & 47 & 42.4 & 41.9 & 38.4 \\
\hline
\end{tabular}

Jika tabel 2. Digambarkan dalam bentuk grafik, sebagai berikut

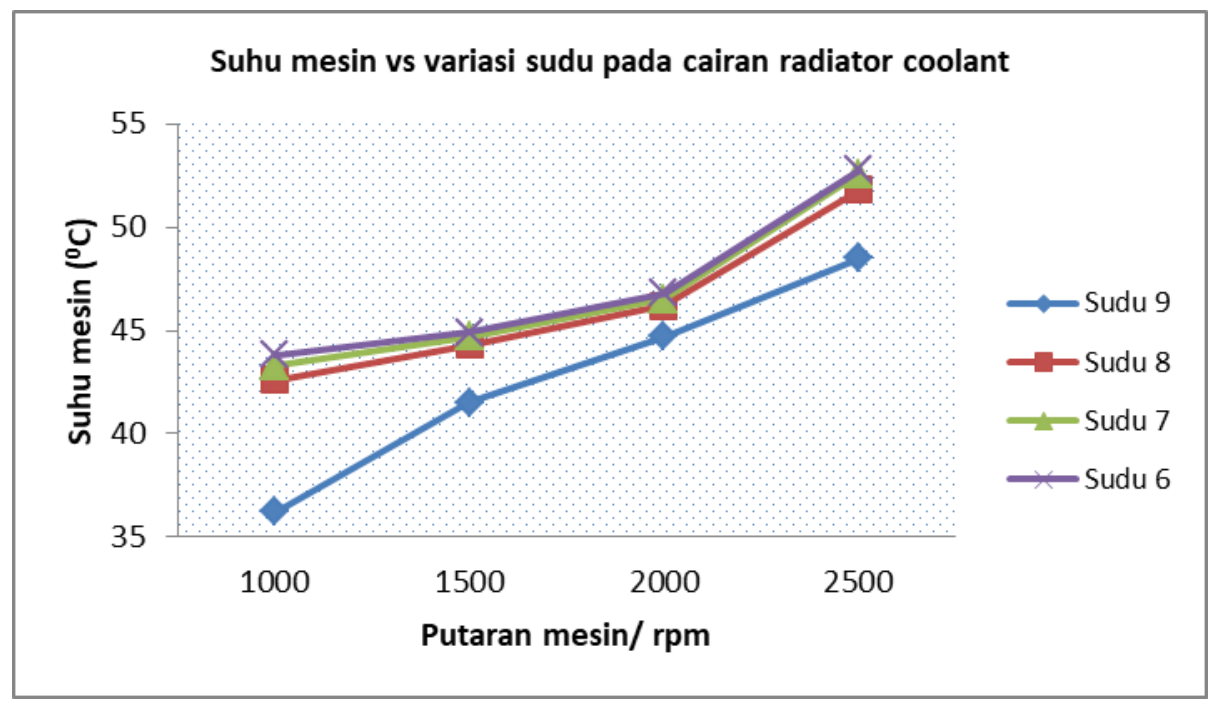

Gambar 4. Grafik pengaruh jumlah sudu terhadap suhu mesin

Pada grafik 4. Terlihat ada kenaikan laju perpindahan panas yang signifikan yaitu sekitar 1,35 \% pada sudu 6 , kenaikan 1,40 \% pada sudu 7, kenaikan 3,05\% pada sudu 8 sekitar 3,83 \% pada sudu 9, terjadi peningkatan laju perpindahan panas yang sangat kecil, sudu 9 memiliki nilai optimum di banding dengan sudu yang lain pada pengujian ini. Sehungga setelah melakukan pengujian ini penulis melakukan perlakuan acak pada suhu radiator sebanyak 48 kali stelah dilakukan uji -F, Sehingga didapatkan bahwa:

Hasil dari uji F, Sebagai berikut :

- $\quad$ Efek Faktor A $\quad$ : F hitung $>$ F tabel (0.01) berbeda sangat nyata

- $\quad$ Efek Faktor B : F hitung $<$ F tabel (0.05) berbeda tidak nyata

- $\quad$ Efek Interaksi A x B $\quad$ : F tabel (0.05) $<$ F hitung $<$ F tabel (0.01) tidak nyata

- $\quad$ Nilai $\left(\mathrm{F}_{\text {interaksi }}=-8.24\right)<$ nilai $\mathrm{F}_{0.05(\mathrm{db} 1=12)}=1.96$, sehingga pada taraf nyata $\alpha=5 \%$ tidak terjadi pengaruh interaksi antara salah satu perubahan jumlah sudu dengan suhu mesin nyata 
Tabel 3. Data hasil pengujian konsumsi bahan bakar terhadap variasi jumlah sudu dan putaran mesin

\begin{tabular}{|c|c|c|c|c|c|}
\hline \multirow{2}{*}{$\begin{array}{c}\text { Jenis } \\
\text { cairan }\end{array}$} & \multirow{2}{*}{$\begin{array}{c}\text { Rpm } \\
\text { (n) }\end{array}$} & \multicolumn{4}{|c|}{ Unit aktivitas Jumlah sudu } \\
\cline { 3 - 6 } & & 6 & 7 & 8 & 9 \\
\cline { 3 - 6 } & $\mathrm{q}^{0}$ & $\mathrm{q}^{0}$ & $\mathrm{q}^{0}$ & $\mathrm{q}^{0}$ \\
\hline \multirow{2}{*}{$\begin{array}{c}\text { Radiator } \\
\text { coolant } \\
\text { yang } \\
\text { mengand } \\
\text { ung } \\
\text { ethylene } \\
\text { glycol }\end{array}$} & 1000 & 451.7 & 420.6 & 415.7 & 410 \\
\cline { 2 - 6 } & 2000 & 570.5 & 465.3 & 450.2 & 440 \\
\cline { 2 - 6 } & 2500 & 642.4 & 560.6 & 503.4 & 490 \\
\hline \multicolumn{2}{|c|}{ Jumlah } & 2140.3 & 1892.6 & 1799.9 & 1760 \\
\hline \multicolumn{2}{|c|}{ Rata - rata } & 535 & 473 & 456.8 & 440 \\
\hline
\end{tabular}

Bentuk grafik konsumsi bahan bakar dengan variasi sudu sebagai berikut :

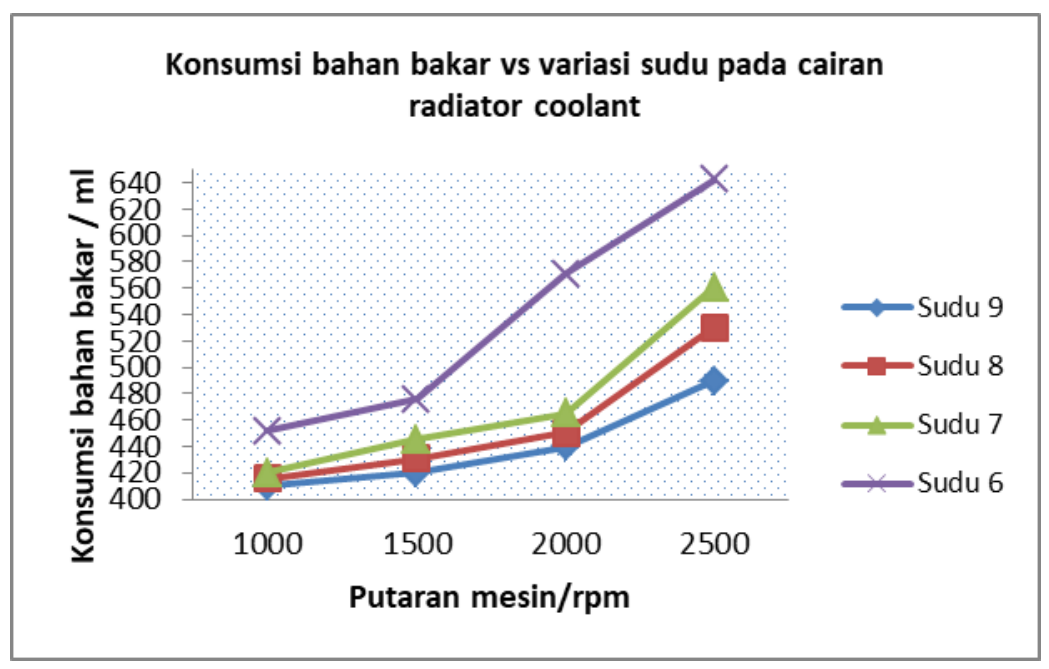

Gambar 5. Grafik pengaruh jumlah sudu terhadap konsumsi bahan bakar pada cairan radiator coolant.

Pada gambar 5.Pada grafik ini menjelaskan sudu 6 menghabiskan 5,35 \% atau sekitar 535 ml sekali pengujian pada sudu 7 menghabiskan 4,73\% atau sekitar 456 ml, pada sudu 8 sekitar 4,56 \% atau sekitar 456 ml dan pada sudu 9 sekitar 4,40 \% atau sekitar $440 \mathrm{ml}$. Setelah melakukan pengacakan pada suhu radiator sebanyak 48 kali, maka didapatkan hasil Uji - F sebgaia berikut :

Hasil dari uji F, Sebagai berikut :

- $\quad$ Efek Faktor A

: F hitung $>$ F tabel (0.01) berbeda sangat nyata

- $\quad$ Efek Faktor B

: F hitung $<$ F tabel $(0.05)$ berbeda tidak nyata

- $\quad$ Efek Interaksi A x B

: F tabel $(0.05)<$ F hitung $<$ F tabel (0.01) tidak nyata 
Nilai $\left(\mathrm{F}_{\text {interaksi }}=-8.24\right)<$ nilai $\mathrm{F}_{0.05(\mathrm{db} 1=12)}=1.96$, sehingga pada taraf nyata $\alpha=5 \%$ tidak terjadi pengaruh interaksi antara salah satu perubahan jumlah sudu dengan konsumsi bahan bakar nyata

Pada pembahasan grafik ini bahwa ada beberapa catatan penting untuk di kembangkan, antara lain ;

a. Pada cairan yang mengandung additive ini mempunyai nilai titik didih yang stabil baik pada sudu 6, sudu 7, sudu 8 dan sudu 9 buah. Juga pada cairan ini sangat berpengaruh pada sistem kinerja pendinginan. Sudu yang mempunyai nilai optimum ada pada sudu 9

b.Aliran debit air terukur pada tiap putaran mesin berbeda, pada sudu 6 sekitar $0.024 \mathrm{~m}^{3} / \mathrm{s}$, pada sudu 7 sekitar $0,029 \mathrm{~m}^{3} / \mathrm{s}$, pada sudu 8 sekitar $0.031 \mathrm{~m}^{3} / \mathrm{s}$ dan pada sudu 9 sekitar $0.042 \mathrm{~m}^{3} / \mathrm{s}$.

c. Data temperatur $\mathrm{Th}_{1}$ tercatat sebesar $=14,7^{\circ} \mathrm{C}$ dan suhu mesin sebesar $\mathrm{Tc}_{1}=4,3{ }^{\circ} \mathrm{C}$

$>$ Menurut Kreith, F.,1976 Harga konduktivitas kalor pada logam paduan berkisar antara $14-120$ $\mathrm{W} / \mathrm{m}^{0} \mathrm{C}$. Harga konduktivitas kalor pada logam paduan tergantung atas :

a. Komposisi bahan

b. Perlakuan panas

c. Temperatur

Harga konduktivitas kalor pada logam paduan jauh lebih rendah dari pada logam murni

> Pendinginan udara terbuka, udara yang terkena konveksi selalu naik ke atas akibat perbedaan rapat jenis udara dingin lebih tinggi dari udara kalor, sehingga udara dingin menekan udara panas, dan dengan cepat menempati ruang yang di tinggalkan oleh udara kalor. Pada akhirnya gradien suhu yang disediakan oleh udara selalu tinggi. Hal ini menyebabkan laju perpindahan kalor dari sampel lebih besar. Besarnya laju perpindahan kalor ini mengakibatkan bentuk butir yang relatif kecilkecil dan struktur dendrit (menerima dan menghantarkan panas) yang kecil,

> Pendinginan oli paling tinggi viskositasnya, sehingga partikel-partikel oli paling lambat bergerak meninggalkan permukaan kalor dan pada akhirnya gradien suhu yang disediakan oli merupakan gradien yang kecil. Pendinginan dengan oli akan menghasilkan bentuk butir yang paling besar dan dendrit yang paling sempurna. Hal ini mengakibatkan pendinginan dengan oli menghasilkan nilai konduktivitas yang lebih besar (Nasser, S.A.,1996) ${ }^{[13]}$

$>$ Suhu dalam motor bensin pada dinding silinder / mantel jaket / water jacket (pendinginan air) sekitar $05-125^{0} \mathrm{C}$ (Daryanto,Teknik Otomotif-Ed.7, Cet.7.- Jakarta : Bumi Aksara, 2002) ${ }^{[14]}$

Alat yang digunakan dalam pengukuran ini dinilai telah dikalibrasi sampai dengan hasil kalibrasi .

\section{KESIMPULAN}

1. Jumlah sudu sangat berpengaruh terhadap kinerja sistem pendingin mesin, dan konsumsi bahan bakar.

2. Jumlah sudu mempunyai nilai optimal terhadap sistem pendingin mesin, pada taraf kepercayaan 95\%, kita menolak Ho $: \mu 1=\mu 2$ bahwa perubahan jumlah sudu sangat berpengaruh terhadap suhu dan konsumsi.

3. Hasil Uji - F adalah melihat beberapa faktor pengaruh yang banyak dari hasil pengacakan baik suhu radiator, suhu mesin dan konsumsi bahan bakar.

4. Dari hasil pengujian ini penulis berharap agar penelitian ini bisa diteruskan kepenelitian yang lebih spesifik dari segi kelayakan alat pengujian.

\section{DAFTAR PUSTAKA}

1. B. P. Statistik, “Jumlah kendaraan di Indonesia selalu meningkat, data Badan Pusat Statistik (BPS),” 2010.

2. Suhartoyo and J. Y. Prihatin, “'Kajian Tentang Jumlah Sudu dan Jarak Kipas Pendingin Terhadap Unjuk Kerja Pendingin Radiator,” 2015. 
3. Daryanto, “'Pemeliharaan sistem pendingin dan pelumasan mobil’ Bandung, penerbit CV Yrama Widya,” 2004.

4. RS. Northop, “'Servis Auto Mobil’. Pustaka Setia, Lingkar Selatan - Bandung,” 1997.

5. “Arismunandar, Wiranto; Tsuda, Koichi 'Motor Diesel Putaran Tinggi', Cetakan ke delapan, Pradnya Paramita, Jakarta.,” 1997.

6. Daryanto, “” Reparasi sistim Pendingin pada Mobil” Jakarta : PT. Rineka Cipta.,” 1994.

7. S. Cao, G. Peng and Z. Yu, “Hydro Dynamics design of roto Dynamics pump impeller for multiphase pumping by combined approach of inverse design and CFD analysis, ASME Transactions', Journal of Fluids Engineering.,” 2005.

8. Kompas Otomotif, “Cairan AC menjadi paradigma pada bengkel dan masyarakat”,” 2015.

9. Astra Motor, “”New Step 1Training Manual book “,. Jakarta PT. TOYOTA ASTRA MOTOR TRAINING CENTER.,” 1995.

10. Thoharudin and S. U. Arif Setyo Nugroho, “’'Optimasi Tinggi Tekan dan Efisiensi Pompa Sentrifugal dengan Perubahan jumlah sudu Impeller dan sudu Keluar Impeller ( $\beta 2)$ menggunakan Simulasi CFD” ISSN: 1979911X.," 2014.

11. suyono, “'Pengaruh jumlah sirip tabung pendingin terhadap konsumsi bahan bakar pada motor diesel stasioner’, Surakarta,Universitas Surakarta.,” 2010.

12. W. Suyanto, “Teori Motor Bensin. DEPDIKBUD: Jakarta,” 1989.

13. Dewan Standarisasi Nasional, “'Dewan Standarisasi Nasional' badan yang menetapkan SNI sebagai standar teknis di Indonesia yang dibentuk Keppres No. 13 Tahun 1977 yang disempurnakan dengan Keppres No. 166 Tahun 2000. Wikipedia bahasa indonesia.,”

14. Daryanto, “,Teknik Otomotif-Ed.7, Cet.7.- Jakarta : Bumi Aksara,” 2002. 